\title{
The Impact of Financial Constraint on the Private Enterprises' OFDI
}

\author{
Xuhong Gong* \\ School of PHBS, Peking University, P.R.China \\ gongxuhong110@163.com \\ *corresponding author
}

Keywords: Financial constraints; OFDI; Extensive margin; Intensive margin

\begin{abstract}
Financial constraint is the primary problem for the private OFDI enterprises. In the help of China's private enterprises "going out" and competitiveness survey data, we test the bivariate marginal effects of financial constraint on enterprise's OFDI. The conclusion found that financial constraint is the important factor for the extensive margin of private enterprises' OFDI, however the impact of financial constraint on private enterprise's OFDI intensive margin is not significant.
\end{abstract}

\section{Introduction}

In recent years, the pace of Chinese enterprises OFDI has speeding up, according to UNCTAD statistics of world investment report journal. The 2015 foreign investment bulletin shows that the total amount of foreign direct investment was $\$ 118$ billion in 201. According to the bulletin, the non-public economy accounted for 65.3 percent of China's OFDI. The private sector has become an indispensable force for Chinese enterprises to "go out".

Although the pace of private enterprises' going abroad has been accelerated, private enterprises have faced many difficulties in the process of OFDI. According to Chinese enterprises overseas investment situation and intention survey report 2013, financial constraint is the primary problem for the outward private enterprises. The literature on the impact of corporate financial constraint on enterprises' outward foreign investment is still lacking. Buch et al. (2009), using the data from Germany's research found that financial constraint and productivity have impact on the firms' OFDI decisions. Maeseneire and Claeys (2011), based on the financial data of enterprises, find that the financial constraint hinders the outward direct investment of enterprises. Buckely et al. (2007) found that the imperfection of capital market and corruption were the important factors affecting China's outward foreign direct investment.

Based on this, this paper used the survey data of "going out" and competitiveness of China's private enterprises, and further analyzed the influence of financial constraint on private OFDI enterprises. The following structure is arranged as follows: the second section is the model setting and indicators. The third section is the analysis of empirical results. Finally, the conclusion.

\section{Model setting and specification}

\subsection{Model setting}

This section mainly studied the influence of financial constraint on the OFDI of enterprises. This paper adopts the model of Heckman (1979). The first stage is the OFDI selection model, and the second stage is the OFDI quantity model.

Based on the studies of Berman and Hericourt (2010), Minetti and Zhu (2011) who used the model to do the trade related research, we set the model as follows: 


$$
\operatorname{Prob}\left(\text { ofdi } i_{i t}>0\right)\left\{\begin{array}{l}
1 \text { if } \alpha_{0}+\alpha_{1} \text { constr }_{i i}+\alpha_{2} \text { TFP }_{i t}+\beta_{1} K_{i t}+\beta_{2} \text { age }_{i t}+\beta_{3} \text { size }_{i t} \\
+\beta_{4} \text { subsidy }_{i t}+\beta_{5} \text { profit }_{i t}+\beta_{6} \text { own }_{i t}>0 \\
0 \quad \text { otherwise }
\end{array}\right.
$$

ofd $_{i t}$ is a dual variable, and $o f d i_{i t}=1$ represents enterprises to invest abroad, vice versa. The main core explanatory variable is the financial constraint constr $r_{i t}$ and total factor productivity $T F P_{i t}$. $K_{i t}$ denotes the capital intensity, age $_{i t}$ is the age of the enterprises, size $_{i t}$ is the scale of the firm, subsidy $y_{i t}$ is the dual variable which represents the firm obtains the subsidy, profit ${ }_{i t}$ is the enterprise's profit, $o w n_{i t}$ is the ownership variable, $\lambda_{j}$ is the region fixed effect, $\lambda_{t}$ is the time fixed effect.

To revise the quantity of OFDI, the second stage is to further investigate the influences of the firms' OFDI quantities. The model is set as:

$$
\begin{aligned}
& \text { Out }_{i t}=\alpha_{0}+\alpha_{1} \text { constr }_{\text {it }}+\alpha_{2} \text { TFP }_{i t}+\beta_{1} K_{i t}+\beta_{2} \text { age }_{i t}+\beta_{3} \text { size }_{i t}+\beta_{4} \text { subsidy }_{i t}+\beta_{5} \text { profit }_{i t}+\beta_{6} \text { brand }_{i t} \\
& +\beta_{7} \text { human }_{i t}+\beta_{8} \text { culture }_{i t}+\beta_{9} \text { fin }_{i t}+\lambda_{j}+\lambda_{t}+\varepsilon_{i t}
\end{aligned}
$$

As for model (2), we just select the sample of OFDI firms, and the dependent variable is the ratio of outward foreign investment volume to sales.

\subsection{Data}

Private economy research center of Chinese academy of social sciences carried the questionnaire survey for China's private enterprises "going out" and competitiveness, which included the data of 706 private enterprises in 2005-2008. This paper uses the questionnaire survey data to carry out the related research.

Financial constraint. In the full reference Hericourt (2010), Spaliara (2009), Minetti and Zhu (2011), we select the enterprise liquidity as a proxy index of the cash flow, to analyze enterprise financial constraint on the influence of foreign direct investment. Total factor productivity. This paper used fixed effect to measure the total factor productivity of the enterprise. Other explanatory variables. (1) we choose enterprise logarithm of total assets to measure enterprise scale. (2) Capital intensity is measured by the ratio of enterprise fixed assets and employees. (3) Age is measured by the length of the enterprises' age, which represents the enterprise's degree of maturity and strong ability to resist risks. ( 3 brand $_{i t}$ is measured by the dual variable whether the brand is registered internationally. (4) profit (5) human it is measured by the dual variable whether there is senior management personnel in the OFDI enterprises (6) culture $_{i t}$ is measured by whether the enterprise conducts social welfare activities in the host country or not.

\section{Empirical results}

\subsection{The extensive margin}

Table 1 adopts profit method to estimate the impact of financial constraint on extensive margin of OFDI. The results show that internal liquidity and foreign investment extensive marginal is positively related, and the regression results is positive at $1 \%$ significance level. This shows that the enterprises' OFDI decisions are influenced by its internal liquidity. A study by Helpman et al. (2004) suggests that the most productive companies choose to invest abroad. The empirical results of this paper support the relevant research. Table 1 shows TFP is an important factor that influences the foreign investment of enterprises. 
Table 1 Financing constraint and the extensive margin of OFDI

\begin{tabular}{c|c|c|c|c}
\hline \multirow{2}{*}{ Variable $^{\mid}$} & \multicolumn{2}{|c|}{ Extensive Margin } & \multicolumn{2}{c}{ Intensive Margin } \\
\cline { 2 - 5 } & Profit & Profit-IV1 & OLS & 2SLS-IV1 \\
\hline constr $_{\text {it }}$ & $0.1632^{* *}(1.98)$ & $0.211^{* * *}(2.56)$ & $-0.1021(-0.61)$ & $-0.7149(-0.88)$ \\
TFP $_{i t}$ & $0.175^{* * *}(2.45)$ & $0.326^{* * *}(2.83)$ & $0.203^{* *}(2.16)$ & $0.3103^{* * *}(2.54)$ \\
$K_{i t}$ & $0.091(0.74)$ & $0.023(0.83)$ & $0.009(0.93)$ & $0.016(1.16)$ \\
age $_{i t}$ & $0.105^{* * *}(2.35)$ & $0.082^{* *}(1.95)$ & $0.28^{* * *}(2.33)$ & $0.33^{* * *}(2.38)$ \\
size $_{i t}$ & $0.117^{* * *}(2.49)$ & $0.193^{* * *}(2.10)$ & $0.053^{* * *}(2.47)$ & $0.124 * * *(3.80)$ \\
profit $_{i t}$ & $0.115^{* *}(1.86)$ & $0.109^{* *}(1.75)$ & $0.023(0.30)$ & $0.038(0.35)$ \\
brand $_{i t}$ & $0.112^{*}(1.74)$ & $0.168^{* *}(1.82)$ & $0.082(0.42)$ & $0.255(1.00)$ \\
human $_{i t}$ & $0.674^{* * *}(4.90)$ & $0.549^{* * *}(3.32)$ & $0.269^{* *}(2.31)$ & $0.267 * * 2.13)$ \\
culture $_{i t}$ & $0.251^{* *}(1.94)$ & $0.250^{* *}(1.78)$ & $0.229(0.97)$ & $0.315^{*}(1.13)$ \\
fin $_{i t}$ & $0.156(1.04)$ & $0.129(1.71)$ & $0.221(1.11)$ & $0.214(0.96)$ \\
$C$ & $-0.510(-0.88)$ & $-0.282(-2.43)$ & $-0.558(-0.64)$ & $-1.056(-0.88)$ \\
PseudoR2 $_{\text {Wald test }}$ & 0.151 & 0.143 & & 10.32 \\
p-value & & 7.52 & & 0.0053 \\
Sample & & 0.0061 & 132 & 132 \\
\hline
\end{tabular}

Note: * Significance at $10 \%$ level; **Significance at 5\% level; *** Significance at $5 \%$ level.

Capital intensity of the impact of foreign investment enterprise is positive, but the regression results didn't pass the significance level test, which shows that capital intensity is not the main factors influencing the enterprise overseas investment. The profit is positive at the significance level of $5 \%$. Age and enterprise scale are the important factors that affect private enterprise overseas investments. The dual variables such as brand, culture have a significant positive effect on the foreign investment of private enterprises, which is in line with our expectations.

There may be endogenous problems between financial constraint and enterprises' foreign investment decisions. Although we have tried to control a series of characteristic variables of the enterprise, there still exist missing variables' problem. So, we selected the quartile variable of the areas and industry as the instrumental variable of enterprise financial constraint variables (Fisman and Svensson, 2007). The variable can overcome endogenous problems caused by missing variables to some extent, and then we use Wald test to test the validity of this instrumental variable.

\subsection{The intensive margin}

The samples we use are only sub-samples of foreign investment enterprises. The regression results are shown in table1. The regression results are not significant, this suggests that internal liquidity is abundant, the less enterprise external large-scale foreign direct investment. This is very different from our basic assumptions, and often companies with more cash flow have the strength to make large-scale outbound investment.

With the help of the quartile variable of the areas and industry as the instrumental variable. Foreign investment enterprises and intensive marginal effect is negative. We analyse the foreign investment enterprises of raw data, found that in 142 samples of foreign invested enterprises, more than $60 \%$ of the investment of foreign enterprises strategic aim is to avoid the fierce competition in the domestic, which suggests that, in the domestic market competition is intense to promote foreign direct investment enterprises. This part also verified the "institution escape theory", namely the enterprise financial constraint on enterprise's foreign investment intensive marginal has certain inhibitory effect.

\section{Conclusion}

Serious ownership discrimination exists in our country. The private enterprises lack collateral and credit foundation, so they mainly rely on their own reserves for OFDI. Therefore, the private 
sector faces higher financial constraint than state-owned enterprises in the process of foreign investment.

This paper analyses the impact of financial constraint on private OFDI in accordance with the survey data of 2008. First, we found that the impact of liquidity on the extensive marginal is positive, based on the theory of information asymmetry, financial constraint are the important factors influencing the extensive marginal of OFDI enterprises. And the impact of financial constraint on the intensive margin is negative. This part also verified the "institution escape theory", namely the enterprise financial constraint on enterprise's foreign investment intensive marginal has inhibitory effect.

\section{Acknowledgments}

This work was financially supported by China Postdoctoral Science Foundation Fund (211110571).

\section{References}

[1]. Berman N, Hricourt J. Financial Factors and the Margins of Trade: Evidence from Crosscountry Firm- level Data [J]. Journal of Development Economics, 2010, 93 (2): 206- 217.

[2]. Buch C M, Kesternich I, Lipponer A, et al. Exports versus FDI revisited: does finance matter? [J]. 2010.

[3]. Chaney, T. Liquidity Constrained Exporters [J]. University of Chicago mimeo, 2005.

[4]. Minetti Raoul, Susan Zhu. Credit Constraints and Firm Export: Microeconomic Evidence from Italy [J]. Journal of International Economics,2011,83 (2):109- 125. 